\title{
Application of the Homotopy Perturbation Method for Solving the Foam Drainage Equation
}

\author{
Abdolhosein Fereidoon, Hessameddin Yaghoobi, \\ and Mohammadreza Davoudabadi
}

Faculty of Mechanical Engineering, Semnan University, Semnan, Iran

Correspondence should be addressed to Hessameddin Yaghoobi, yaghoobi.hessam@gmail.com

Received 8 May 2011; Revised 4 June 2011; Accepted 9 June 2011

Academic Editor: D. D. Ganji

Copyright (C) 2011 Abdolhosein Fereidoon et al. This is an open access article distributed under the Creative Commons Attribution License, which permits unrestricted use, distribution, and reproduction in any medium, provided the original work is properly cited.

We use homotopy perturbation method (HPM) to handle the foam drainage equation. Foaming occurs in many distillation and absorption processes. The drainage of liquid foams involves the interplay of gravity, surface tension, and viscous forces. The concept of He's homotopy perturbation method is introduced briefly for applying this method for problem solving. The results of HPM as an analytical solution are then compared with those derived from Adomian's decomposition method (ADM) and the variational iteration method (VIM). The results reveal that the HPM is very effective and convenient in predicting the solution of such problems, and it is predicted that HPM can find a wide application in new engineering problems.

\section{Introduction}

Most scientific problems and physical phenomena occur nonlinearly. Except in a limited number of these problems, finding the exact analytical solutions of such problems are rather difficult. Therefore, there have been attempts to develop new techniques for obtaining analytical solutions which reasonably approximate the exact solutions [1]. In recent years, several such techniques have drawn special attention, such as Hirota's bilinear method [2], the homogeneous balance method [3, 4], inverse scattering method [5], Adomian's decomposition method (ADM) $[6,7]$, the variational iteration method (VIM) $[8,9]$, and homotopy analysis method (HAM) [10] as well as homotopy perturbation method (HPM).

The homotopy perturbation method was established by He [11]. The method has been used by many authors to handle a wide variety of scientific and engineering applications to solve various functional equations. In this method, the solution is considered as the sum of an infinite series, which converges rapidly to accurate solutions. Recently, considerable research 


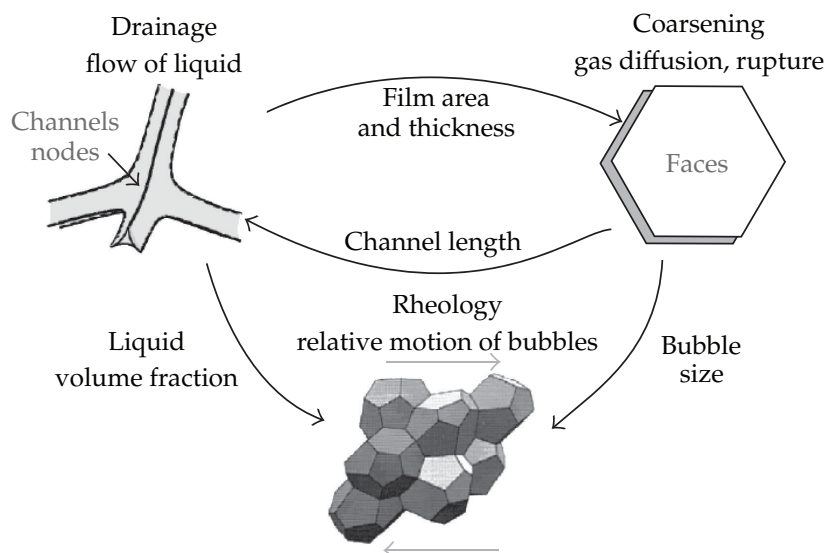

Figure 1: Schematic illustration of the interdependence of drainage, coarsening, and rheology of foams [31].

work has been conducted in applying this method to the linear and nonlinear equations [1225].

Foams are of great importance in many technological processes and applications, and their properties are subject of intensive studies from both practical and scientific points of view [26]. Liquid foam is an example of soft matter (or complex fluid) with a very welldefined structure that first clearly described by Joseph plateau in the 19th century. Weaire et al. [27] showed in their work simple answers to many such questions exist, but no going experiments continue to challenge our understanding. Foams and emulsions are wellknown to scientists and the general public alike because of their everyday occurrence [28, 29]. Foams are common in foods and personal care products such as creams and lotions, and foams often occur, even when not desired, during cleaning (clothes, dishes, scrubbing) and dispensing processes [30]. They have important applications in the food and chemical industries, firefighting, mineral processing, and structural material science [31]. Less obviously, they appear in acoustic cladding, lightweight mechanical components, and impact absorbing parts on cars, heat exchangers, and textured wallpapers (incorporated as foaming inks) and even have an analogy in cosmology. The packing of bubbles or cells can form both random and symmetrical arrays, such as sea foam and bees' honeycomb. History connects foams with a number of eminent scientists, and foams continue to excite imaginations [32]. There are now many applications of polymeric foams [33] and more recently metallic foams, which are foams made of metals such as aluminum [34]. Some commonly mentioned applications include the use of foams for reducing the impact of explosions and for cleaning up oil spills. In addition, industrial applications of polymeric foams and porous metals include their use for structural purposes and as heat exchange media analogous to common "finned" structures [35]. Polymeric foams are used in cushions and packing and structural materials [36]. Glass, ceramic, and metal foams [37] can also be made and find an increasing number of new applications. In addition, mineral processing utilizes foam to separate valuable products by flotation. Finally, foams enter geophysical studies of the mechanics of volcanic eruptions [30]. Recent research in foams and emulsions has centered on three topics which are often treated separately but are, in fact, interdependent: drainage, coarsening, and rheology; see Figure 1. We focus here on a quantitative description of the coupling of drainage and coarsening. Foam drainage is the flow of liquid through channels (plateau borders) and nodes (intersections 
of four channels) between the bubbles, driven by gravity and capillarity [38-40]. During foam production, the material is in the liquid state, and fluid can rearrange while the bubble structure stays relatively unchanged. The flow of liquid relative to the bubbles is called drainage. Generally, drainage is driven by gravity and/or capillary (surface tension) forces and is resisted by viscous forces [30]. Because of their limited time stability and despite the numerous studies reported in the literature, many of their properties are still not well understood, in particular the drainage of the liquid in between the bubbles under the influence of gravity [41, 42]. Drainage plays an important role in foam stability. Indeed, when foam dries, its structure becomes more fragile; the liquid films between adjacent bubbles being thinner, then can break, leading to foam collapse. In the case of aqueous foams, surfactant is added into water, and it adsorbs at the surface of the films, protecting them against rupture [43]. Most of the basic rules that explain the stability of liquid gas foams were introduced over 100 years ago by the Belgian Joseph Plateau who was blind before he completed his important book on the subject. This modern-day book by Weaire and Hutzler provides valuable summaries of plateaus work on the laws of equilibrium of soap films, and it is especially useful since the original 1873 French text does not appear to be in a fully translated English version. Weaire and Hutzler note that Sir W. Thompson (Lord Kelvin) was simulated by Plateau's book to examine the optimum packing of free space by regular geometrical cells. His solution to the problem remained the best until quite recently. Why does this area of theoretical research, still active today, have connections with the apparently frivolous theme of bubbles? It is because the packing of free space involves the minimization of the surface energy of the structure (i.e., least amount of boundary material). Thus, one might ask why such an often-observed medium as a foam has not provided the optimum solution to this problem much earlier; perhaps, this shows that observation is often biased towards what one expects to see, rather than to the unexpected. Also, in nature, there are packing problems, such as the bees' honeycomb. Its shaped ends provide a nice example of Plateau's rules in a natural environment [32]. Recent theoretical studies by Verbist and Weaire describe the main features of both free drainage $[44,45]$, where liquid drains out of a foam due to gravity, and forced drainage [46], where liquid is introduced to the top of a column of foam. In the latter case, a solitary wave of constant velocity is generated when liquid is added at a constant rate [47]. Forced foam drainage may well be the best prototype for certain general phenomena described by nonlinear differential equations, particularly the type of solitary wave which is most familiar in tidal bores. The model developed by Verbist and Weaire idealizes the network of Plateau borders, through which the majority of liquid is assumed to drain, as a set of $N$ identical pipes of cross section $A$, which is a function of position and time [48]

$$
\frac{\partial A}{\partial t}+\frac{\partial}{\partial x}\left(A^{2}-\frac{\sqrt{A}}{2} \frac{\partial A}{\partial x}\right)=0
$$

where $x$ and $t$ are scaled position and time coordinates, respectively. In the case of forced drainage, the solution can be expressed as [48]

$$
A(x, t)= \begin{cases}c \tanh ^{2}(\sqrt{c}(x-c t)) & x \leq c t \\ 0 & x \leq c t\end{cases}
$$

where $c$ is the velocity of the wave front [46]. 
The pursuit of analytical solutions for foam drainage equation is of intrinsic scientific interest. To the best of the authors' knowledge, there is no paper that has solved the nonlinear foam drainage equation by HPM. In this paper, the basic idea of HPM is described, and then, it is applied to study the following nonlinear foam drainage equation [49]. Finally, the results of HPM as an analytical solution are then compared with those derived from Adomian's decomposition method [49] and the variational iteration method [50].

\section{Basic Idea of Homotopy Perturbation Method}

To explain this method, let us consider the following function:

$$
A(u)-f(r)=0, \quad r \in \Omega,
$$

with the boundary conditions of

$$
B\left(u, \frac{\partial u}{\partial n}\right)=0, \quad r \in \Gamma
$$

where $A$ is a general differential operator $f(r)$ is a known analytic function, $B$ is a boundary operator, and $\Gamma$ is the boundary of the domain $\Omega$. The operator $A$ can be generally divided into two operators, $L$ and $N$, where $L$ is a linear and $N$ a nonlinear operator. Equation (2.1) can be, therefore, written as follows:

$$
L(u)+N(u)-f(r)=0 .
$$

Using the homotopy technique, we constructed a homotopy $v(r, p): \Omega \times[0,1] \rightarrow R$, which satisfies

$$
H(v, p)=(1-p)\left[L(v)-L\left(u_{0}\right)\right]+p[A(v)-f(r)]=0,
$$

or

$$
H(v, p)=L(v)-L\left(u_{0}\right)+p L\left(u_{0}\right)+p[N(v)-f(r)]=0,
$$

where $p \in[0,1]$ is called homotopy parameter and $u_{0}$ is an initial approximation for the solution of (2.1), which satisfies the boundary conditions. Obviously, from (2.4) or (2.5), we will have

$$
\begin{aligned}
& H(v, 0)=L(v)-L\left(u_{0}\right)=0 \\
& H(v, 1)=A(v)-f(r)=0 .
\end{aligned}
$$

We can assume that the solution of (2.4) or (2.5) can be expressed as a series in $p$ as follows:

$$
v=v_{0}+p v_{1}+p^{2} v_{2}+\cdots
$$




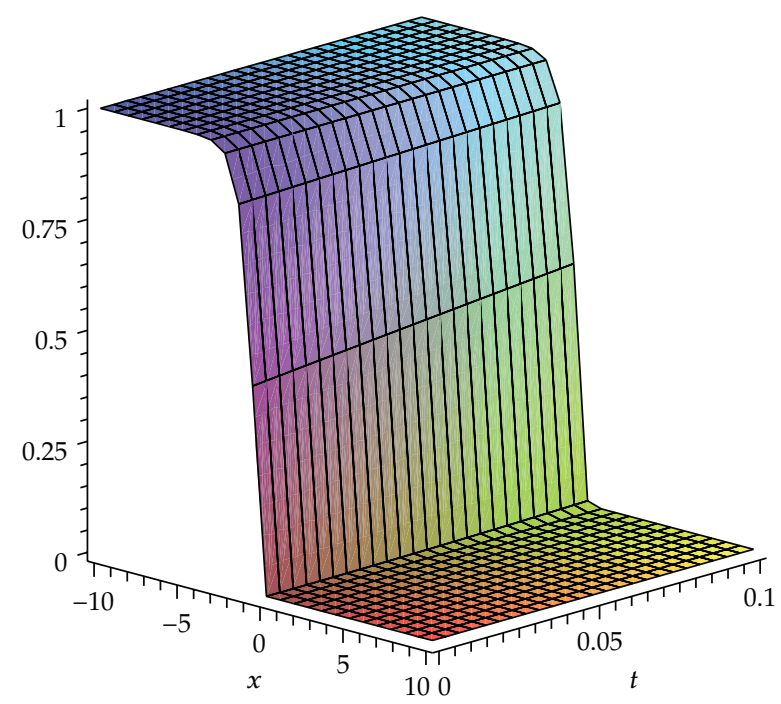

(a)

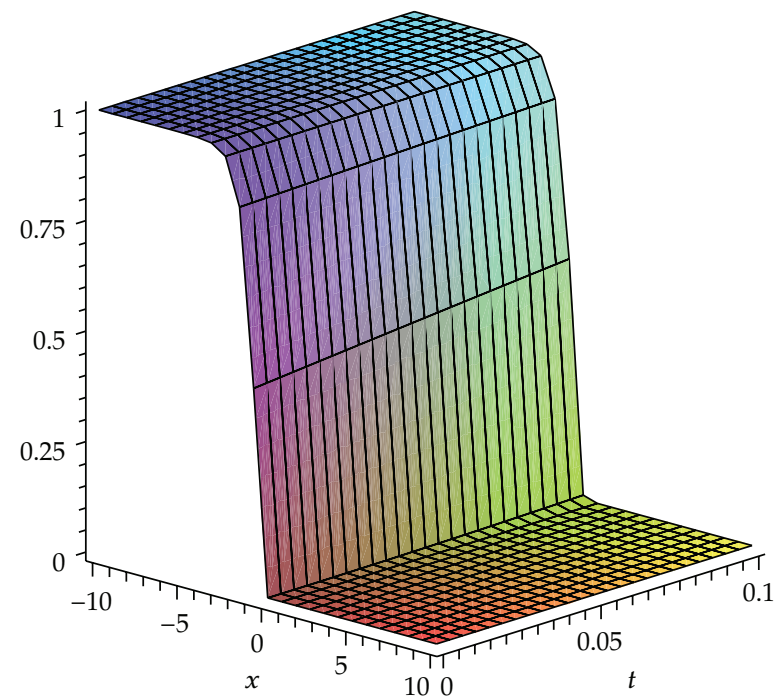

(b)

Figure 2: The solution of (1.1) at $c=1$ (a) HPM (b) Exact.

Setting $p=1$ results in the approximate solution of (2.1)

$$
u=\lim _{p \rightarrow 1} v=v_{0}+v_{1}+v_{2}+\cdots
$$

\section{Implementation of HPM}

In this section, we obtain an analytical solution of (1.1). We first use the transformation

$$
A(x, t)=u^{2}(x, t)
$$




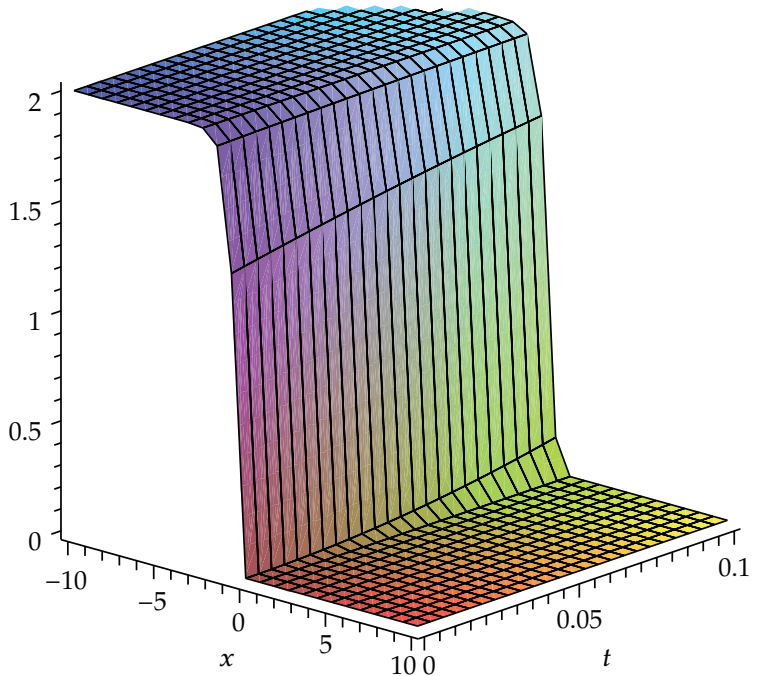

(a)

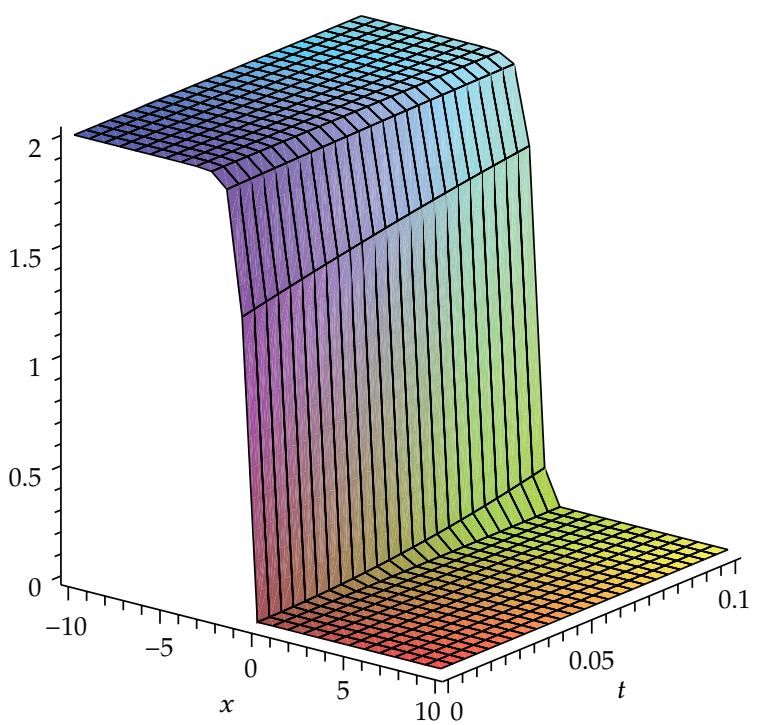

(b)

Figure 3: The solution of (1.1) at $c=2$ (a) HPM (b) Exact.

to convert (1.1) to

$$
u_{t}+2 u^{2} u_{x}-\left(u_{x}\right)^{2}-\frac{1}{2} u_{x x} u=0
$$

with initial condition

$$
u(x, 0)=-\sqrt{c} \tanh (\sqrt{c} x) .
$$




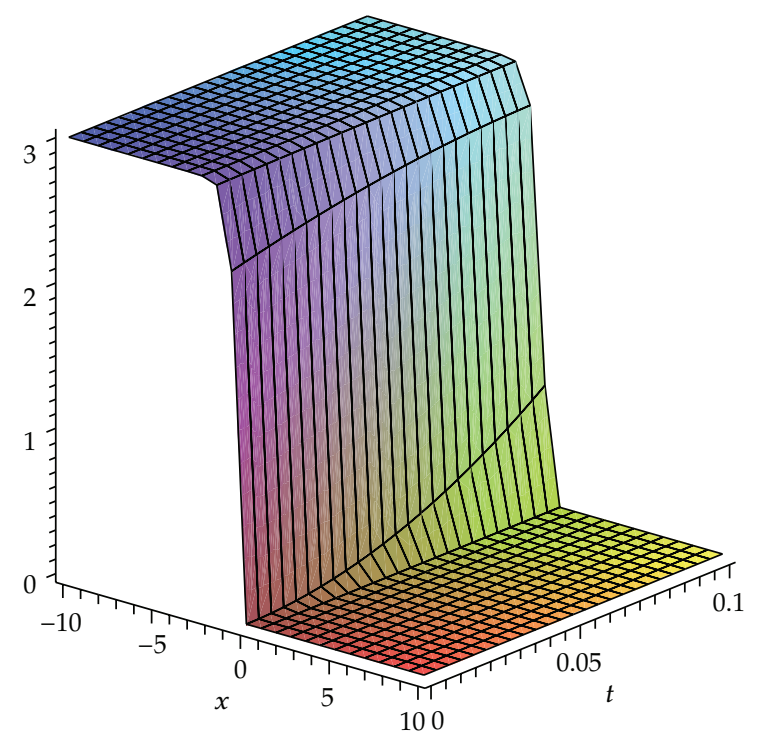

(a)

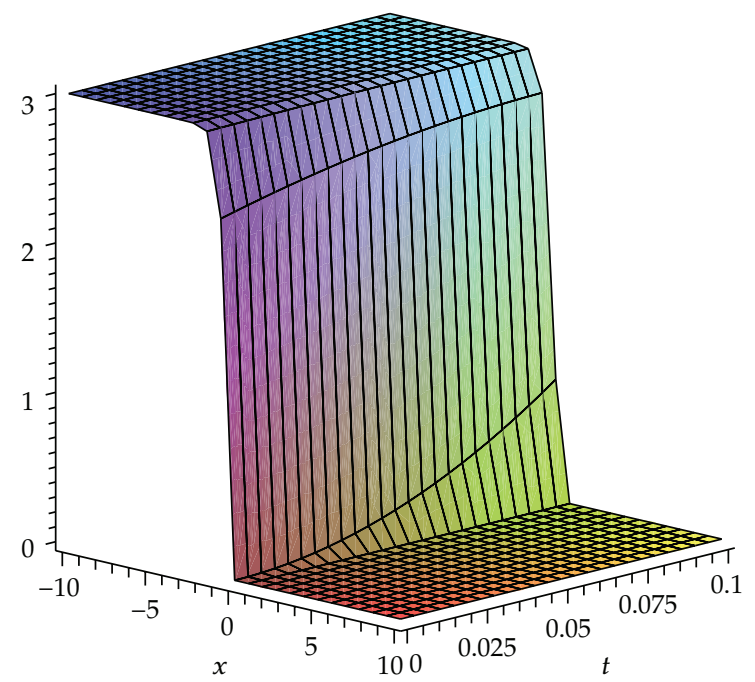

(b)

Figure 4: The solution of (1.1) at $c=3$ (a) HPM (b) Exact.

To solve (3.2) with the initial condition (3.3), according to the homotopy perturbation method, we construct the following He's polynomials corresponding to (2.5):

$$
\begin{gathered}
L(v)=v_{t} \\
N(v)=2 v^{2} v_{x}-\left(v_{x}\right)^{2}-\frac{1}{2} v_{x x} v \\
H(v, p)=v_{t}-u_{0 t}+p u_{0 t}+p\left[2 v^{2} v_{x}-\left(v_{x}\right)^{2}-\frac{1}{2} v_{x x} v\right] .
\end{gathered}
$$




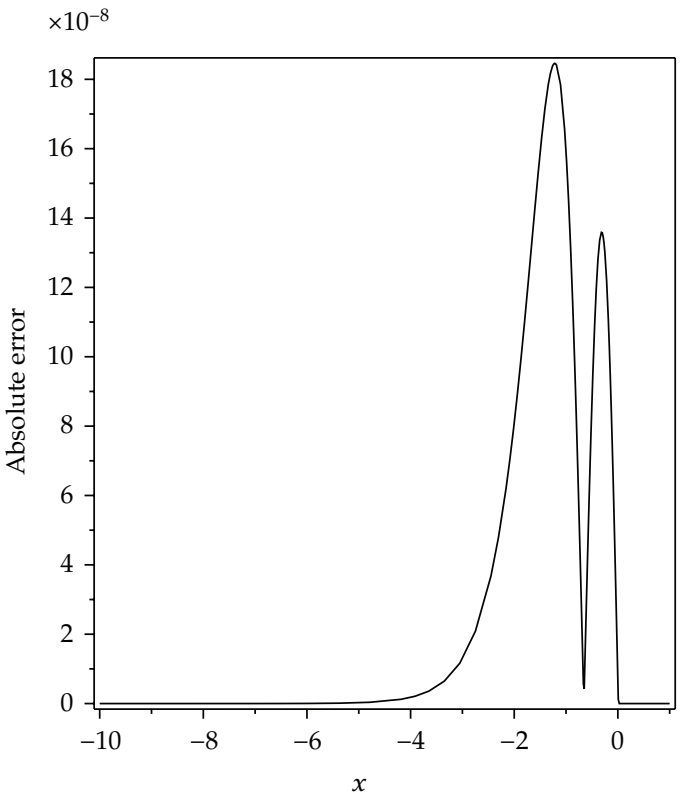

(a)

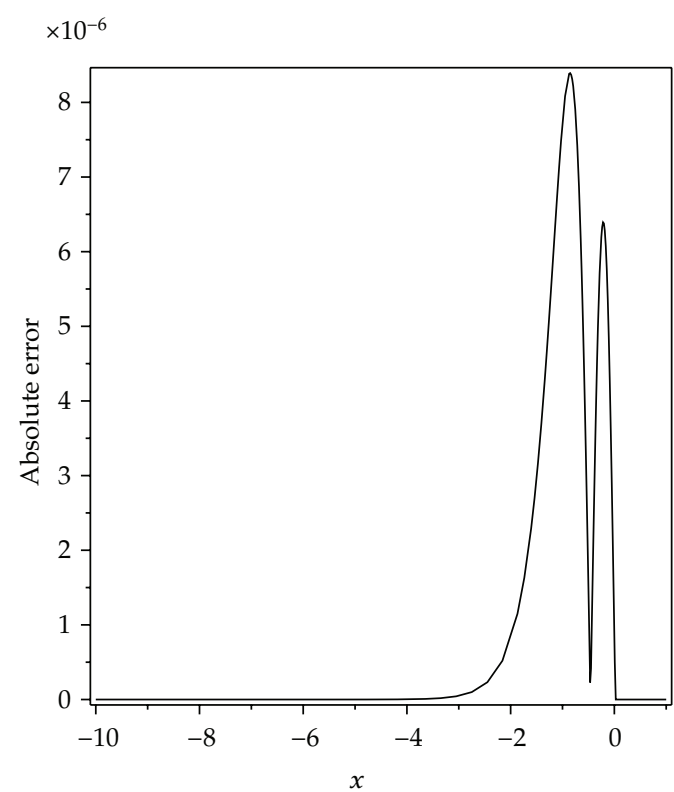

(b)

Figure 5: The absolute error of HPM at $t=0.01$ (a) $c=1$ (b) $c=2$.

Substituting $v=v_{0}+p v_{1}+p^{2} v_{2}+\cdots$ into (3.2) and rearranging the resultant equation based on powers of $p$-terms, one has

$$
\begin{gathered}
p^{0}: v_{0 t}-u_{0 t}=0 \\
p^{1}: v_{1 t}+u_{0 t}+\left[2 v_{0}^{2} v_{0 x}-\left(v_{0 x}\right)^{2}-\frac{1}{2} v_{0 x x} v_{0}\right]=0 \\
p^{2}: v_{2 t}+4 v_{0} v_{1} v_{0 x}+2 v_{0}^{2} v_{1 x}-2 v_{0 x} v_{1 x}-\frac{1}{2} v_{0 x x} v_{1}-\frac{1}{2} v_{1 x x} v_{0}=0
\end{gathered}
$$

with the following conditions:

$$
\begin{aligned}
& v_{0}(x, 0)=-\sqrt{c} \tanh (\sqrt{c} x), \\
& v_{i}(x, 0)=0 \quad \text { for } i=1,2, \ldots
\end{aligned}
$$




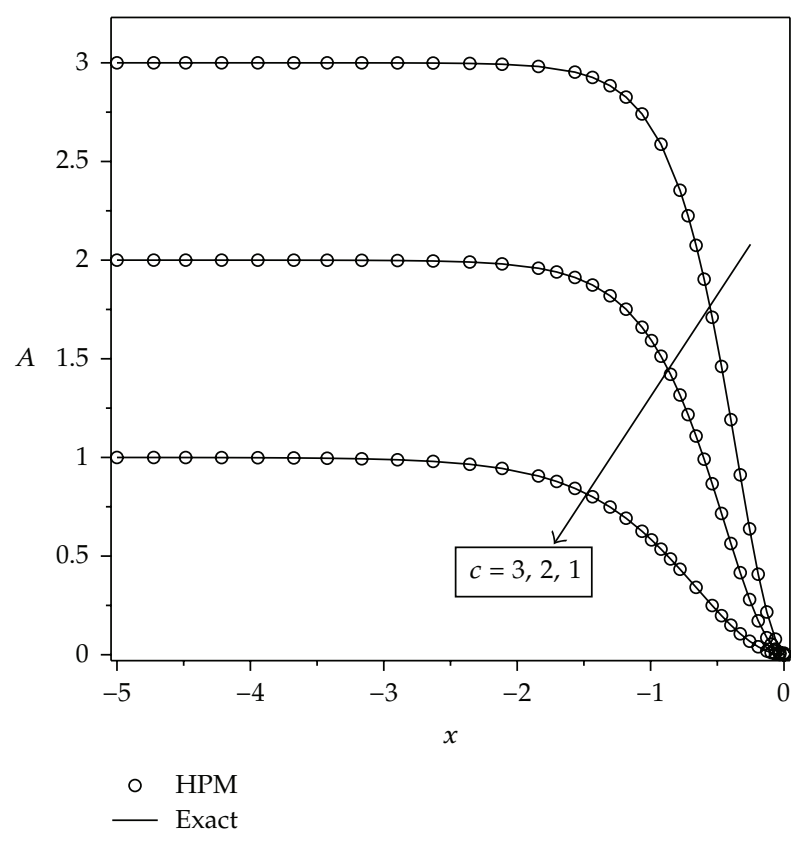

Figure 6: The effect of $c$ at $t=0.01$.

With the effective initial approximation for $v_{0}$ from the condition (3.6), the solutions of (3.5) are obtained as follows:

$$
\begin{gathered}
v_{0}(x, t)=-\sqrt{c} \tanh (\sqrt{c} x) \\
v_{1}(x, t)=\frac{2 c^{2} t}{\cosh (2 \sqrt{c} x)^{2}} \\
v_{2}(x, t)=\frac{c^{7 / 2} t^{2} \sinh (\sqrt{c} x)}{\cosh (\sqrt{c} x)^{3}} .
\end{gathered}
$$

In the same manner, the rest of components were obtained using the Maple package. According to the HPM, we can conclude that

$$
u(x, t)=v_{0}(x, t)+v_{1}(x, t)+v_{2}(x, t) .
$$

Therefore, we will have

$$
u(x, t)=-\sqrt{c} \tanh (\sqrt{c} x)+\frac{2 c^{2} t}{\cosh (2 \sqrt{c} x)^{2}}+\frac{c^{7 / 2} t^{2} \sinh (\sqrt{c} x)}{\cosh (\sqrt{c} x)^{3}}
$$

By substituting (3.10) into (3.1), we can find the solution of (1.1). 
Table 1: Comparison between absolute errors of ADM, VIM, and HPM for $t=0.001, c=3$.

\begin{tabular}{cccc}
\hline$x$ & $A_{\text {exact }}-A_{\mathrm{ADM}}[49]$ & $A_{\text {exact }}-A_{\mathrm{VIM}}[50]$ & $A_{\text {exact }}-A_{\mathrm{HPM}}$ \\
\hline-10 & $4.44089 E-16$ & 0 & 0 \\
-8 & $2.24265 E-13$ & 0 & $2.4 E-18$ \\
-6 & $2.29754 E-10$ & 0 & $2.1059 E-15$ \\
-4 & $2.34498 E-7$ & 0 & $2.14918 E-12$ \\
-2 & 0.000236656 & 0 & $2.17229 E-9$ \\
-1 & 0.00523834 & 0 & $5.10302 E-8$ \\
0 & $5.2479 E-8$ & 0 & $1.45797 E-9$ \\
\hline
\end{tabular}

Table 2: Comparison between absolute errors of ADM, VIM, and HPM for $t=0.01, c=3$.

\begin{tabular}{cccc}
\hline$x$ & $A_{\text {exact }}-A_{\mathrm{ADM}}[49]$ & $A_{\text {exact }}-A_{\mathrm{VIM}}[50]$ & $A_{\text {exact }}-A_{\mathrm{HPM}}$ \\
\hline-10 & $1.77636 E-15$ & 0 & $2.00000 E-18$ \\
-8 & $1.86962 E-12$ & 0 & $2.01600 E-15$ \\
-6 & $1.9087 E-9$ & 0 & $2.05744 E-12$ \\
-4 & $1.94811 E-6$ & $6 E-08$ & $2.09993 E-9$ \\
-2 & 0.00197296 & $6.0881 E-05$ & 0.000002123 \\
-1 & 0.0485679 & - & 0.000050433 \\
0 & 0.00051592 & $8.08544 E-3$ & 0.000014557 \\
\hline
\end{tabular}

\section{Results and Discussion}

In this section, we present the results with HPM to show the efficiency of the method, described in the previous section for solving (1.1). By Figures 2, 3, and 4, we may simply compare the HPM solution and exact solution of (1.1) for $c=1$, respectively. It is easy to verify the accuracy of the obtained results if we graphically compare HPM solutions with the exact ones. The absolute error of HPM is drawn in Figure 5 at $t=0.01$. It can be seen from this figure that the absolute error is very small and the mentioned method is very accurate. The effect of velocity of the wave, $c$, is demonstrated in Figure 6.

It is important to see the difference between the results obtained by ADM [49] and VIM [50] and the results which are obtained by the analytic solution using by the HPM. These can be seen by comparing Tables 1,2 , and 3 . The results which are obtained by the HPM and the exact solutions are quite similar. It is shown the accuracy of the HPM. The solution of the HPM is more accurate than the ADM. While using HPM, the difficulty of calculating Adomian's polynomials does not occur. Another benefit of using the HPM is that the time consumption of the numerical calculation is less than the time consumption of ADM.

\section{Conclusion}

In this work, He's homotopy perturbation method has been successfully utilized to derive approximate explicit analytical solution for the nonlinear foam drainage equation. The results show that this perturbation scheme provides excellent approximations to the solution of this nonlinear equation with high accuracy and avoids linearization and physically unrealistic assumptions. This new method is extremely simple, easy to apply, needs less computation, and accelerates the convergence to the solutions. The results obtained here are compared 
Table 3: Comparison between absolute errors of ADM, VIM, and HPM for $t=0.1, c=3$.

\begin{tabular}{cccc}
\hline$x$ & $A_{\text {exact }}-A_{\mathrm{ADM}}[49]$ & $A_{\text {exact }}-A_{\mathrm{VIM}}[50]$ & $A_{\text {exact }}-A_{\mathrm{HPM}}$ \\
\hline-10 & $1.42109 E-14$ & 0 & $1.59300 E-15$ \\
-8 & $1.40941 E-11$ & 0 & $1.62593 E-12$ \\
-6 & $1.43842 E-8$ & $5 E-09$ & $1.65952 E-9$ \\
-4 & 0.0000146727 & $4.527 E-06$ & $1.69379 E-6$ \\
-2 & 0.0064218 & $4.59239 E-03$ & 0.001716375 \\
-1 & 0.094494 & - & 0.043767689 \\
0 & 3.71367 & $6.8374 E-01$ & 0.126259125 \\
\hline
\end{tabular}

with results of exact solution. The current work illustrates that the HPM is indeed a powerful analytical technique for most types of nonlinear problems and several such problems in scientific studies and engineering may be solved by this method.

\section{Acknowledgments}

The authors gratefully acknowledge the support of the Department of Mechanical Engineering and the talented office of Semnan University for funding the current research grant.

\section{References}

[1] A. H. Nayfeh, Introduction to Perturbation Techniques, John Wiley \& Sons, New York, NY, USA, 1981.

[2] X. B. Hu and Y. T. Wu, "Application of the Hirota bilinear formalism to a new integrable differentialdifference equation," Physics Letters A, vol. 246, no. 6, pp. 523-529, 1998.

[3] E. Fan, "Two new applications of the homogeneous balance method," Physics Letters A, vol. 265, no. 5-6, pp. 353-357, 2000.

[4] M. Wang, Y. Zhou, and Z. Li, "Application of a homogeneous balance method to exact solutions of nonlinear equations in mathematical physics," Physics Letters A, vol. 216, no. 1-5, pp. 67-75, 1996.

[5] V. O. Vakhnenko, E. J. Parkes, and A. J. Morrison, "A Bäcklund transformation and the inverse scattering transform method for the generalised Vakhnenko equation," Chaos, Solitons and Fractals, vol. 17, no. 4, pp. 683-692, 2003.

[6] G. Adomian, "Nonlinear dissipative wave equations," Applied Mathematics Letters, vol. 11, no. 3, pp. 125-126, 1998.

[7] G. Adomian and R. Rach, "Modified decomposition solution of linear and nonlinear boundary-value problems," Nonlinear Analysis, vol. 23, no. 5, pp. 615-619, 1994.

[8] H. Jafari and H. Tajadodi, "He's variational iteration method for solving fractional Riccati differential equation," International Journal of Differential Equations, vol. 2010, Article ID 764738, 2010.

[9] M. T. Darvishi and F. Khani, "Numerical and explicit solutions of the fifth-order Korteweg-de Vries equations," Chaos, Solitons and Fractals, vol. 39, no. 5, pp. 2484-2490, 2009.

[10] S. Liao, "On the homotopy analysis method for nonlinear problems," Applied Mathematics and Computation, vol. 147, no. 2, pp. 499-513, 2004.

[11] J. H. He, "Homotopy perturbation technique," Computer Methods in Applied Mechanics and Engineering, vol. 178, no. 3-4, pp. 257-262, 1999.

[12] D. D. Ganji and A. Rajabi, "Assessment of homotopy-perturbation and perturbation methods in heat radiation equations," International Communications in Heat and Mass Transfer, vol. 33, no. 3, pp. 391-400, 2006.

[13] J. Biazar and H. Ghazvini, "Numerical solution for special non-linear Fredholm integral equation by HPM," Applied Mathematics and Computation, vol. 195, no. 2, pp. 681-687, 2008.

[14] D. D. Ganji and M. Rafei, "Solitary wave solutions for a generalized Hirota-Satsuma coupled KdV equation by homotopy perturbation method," Physics Letters. A, vol. 356, no. 2, pp. 131-137, 2006. 
[15] J. Biazar and H. Ghazvini, "Homotopy perturbation method for solving hyperbolic partial differential equations," Computers \& Mathematics with Applications, vol. 56, no. 2, pp. 453-458, 2008.

[16] D.-H. Shou, "The homotopy perturbation method for nonlinear oscillators," Computers \& Mathematics with Applications, vol. 58, no. 11-12, pp. 2456-2459, 2009.

[17] M. Jalaal, D. D. Ganji, and G. Ahmadi, “Analytical investigation on acceleration motion of a vertically falling spherical particle in incompressible Newtonian media," Advanced Powder Technology, vol. 21, no. 3, pp. 298-304, 2010.

[18] M. Jalaal and D. D. Ganji, "An analytical study on motion of a sphere rolling down an inclined plane submerged in a Newtonian fluid," Powder Technology, vol. 198, no. 1, pp. 82-92, 2010.

[19] M. Jalaal and D. D. Ganji, "On unsteady rolling motion of spheres in inclined tubes filled with incompressible Newtonian fluids," Advanced Powder Technology, vol. 22, no. 1, pp. 58-67, 2011.

[20] M. Jalaal, D. D. Ganji, and G. Ahmadi, "An analytical study on settling of non-spherical particles," Asia-Pacific Journal of Chemical Engineering, 2010.

[21] D. D. Ganji, "The application of He's homotopy perturbation method to nonlinear equations arising in heat transfer," Physics Letters. A, vol. 355, no. 4-5, pp. 337-341, 2006.

[22] D. D. Ganji and A. Sadighi, "Application of He's homotopy-perturbation method to nonlinear coupled systems of reaction-diffusion equations," International Journal of Nonlinear Sciences and Numerical Simulation, vol. 7, no. 4, pp. 411-418, 2006.

[23] A. Fereidoon, D. D. Ganji, and Y. Rostamiyan, "Application of he's homotopy perturbation and variational iteration methods to solving propagation of thermal stresses equation in an infinite elastic slab," Advances in Theoretical and Applied Mechanics, vol. 1, no. 4, pp. 199-215, 2008.

[24] A. Fereidoon, Y. Rostamiyan, M. Akbarzade, and D. D. Ganji, "Application of He's homotopy perturbation method to nonlinear shock damper dynamics," Archive of Applied Mechanics, vol. 80, no. 6, pp. 641-649, 2010.

[25] Y. Rostamiyan, A. Fereidoon, M. R. Davoudabadi, H. Yaghoobi, and D. D. Ganji, "Analytical approach to investigation of deflection of circular plate under uniform load by homotopy perturbation method," Mathematical \& Computational Applications, vol. 15, no. 5, pp. 816-821, 2010.

[26] S. D. Stoyanov, V. N. Paunov, E. S. Basheva, I. B. Ivanov, A. Mehreteab, and G. Broze, "Motion of the front between thick and thin film: hydrodynamic theory and experiment with vertical foam films," Langmuir, vol. 13, no. 6, pp. 1400-1407, 1997.

[27] D. Weaire, S. Hutzler, S. Cox, N. Kern, M. D. Alonso, and D. D. Drenckhan, "The fluid dynamics of foams," Journal of Physics Condensed Matter, vol. 15, no. 1, pp. S65-S73, 2003.

[28] R. K. Prud'homme and S. A. Khan, Foams: Theory, Measurements and Applications, Marcel Dekker, New York, NY, USA, 1996.

[29] D. L. Weaire and S. Hutzler, The Physics of Foams, Oxford University Press, Oxford, UK, 2000.

[30] H. A. Stone, S. A. Koehler, S. Hilgenfeldt, and M. Durand, "Perspectives on foam drainage and the influence of interfacial rheology," Journal of Physics Condensed Matter, vol. 15, no. 1, pp. S283-S290, 2003.

[31] S. Hilgenfeldt, S. A. Koehler, and H. A. Stone, "Dynamics of coarsening foams: accelerated and selflimiting drainage," Physical Review Letters, vol. 86, no. 20, pp. 4704-4707, 2001.

[32] J. I. B. Wilson, "Essay review, scholarly froth and engineering skeletons," Contemporary Physics, vol. 44, pp. 153-155, 2003.

[33] L. J. Gibson and M. F. Ashby, Cellular Solids: Structure E Properties, Cambridge University Press, Cambridge, UK, 1997.

[34] J. Banhart, Metallschaume, MIT, Bermen, Germany, 1997.

[35] S. A. Koehler, H. A. Stone, M. P. Brenner, and J. Eggers, "Dynamics of foam drainage," Physical Review E, vol. 58, no. 2, pp. 2097-2106, 1998.

[36] L. J. Gibson and M. F. Ashby, Cellular Solids: Structure and Properties, Cambridge University Press, Cambridge, UK, 1999.

[37] M. F. Ashby, A. G. Evans, N. A. Fleck, L. J. Gibson, J. w. Hutchinson, and H. N. G. Wasley, Metal Foams: A Design Guide, Society of Automotive Engineers, Boston, Mass, USA, 2000.

[38] R. A. Leonard and R. Lemlich, "A study of interstitial liquid flow in foam," AIChE Journal, vol. 11, pp. 18-29, 1965.

[39] I. I. Gol'dfarb, K. B. Kann, and I. R. Shreiber, "Liquid flow in foams," Fluid Dynamics, vol. 23, no. 2, pp. 244-249, 1988.

[40] D. Weaire and S. Hutzler, The Physics of Foams, Oxford University Press, Oxford, UK, 2000.

[41] D. Weaire, S. Hutzler, G. Verbist, and E. A. J. Peters, "A review of foam drainage," Advances in Chemical Physics, vol. 102, pp. 315-374, 1997. 
[42] A. Bhakta and E. Ruckenstein, "Decay of standing foams: drainage, coalescence and collapse," Advances in Colloid and Interface Science, vol. 70, no. 1-3, pp. 1-123, 1997.

[43] M. Durand and D. Langevin, "Physicochemical approach to the theory of foam drainage," European Physical Journal E, vol. 7, no. 1, pp. 35-44, 2002.

[44] Verbist G. and D. Weaire, "Soluble model for foam drainage," Europhysics Letters, vol. 26, pp. 631-634, 1994.

[45] G. Verbist, D. Weaire, and A. M. Kraynik, "The foam drainage equation," Journal of Physics Condensed Matter, vol. 8, no. 21, pp. 3715-3731, 1996.

[46] G. Verbist and D. Weaire, "Soluble model for foam drainage," Europhysics Letters, vol. 26, pp. 631-641, 1994.

[47] D. Weaire, S. Hutzler, N. Pittet, and D. Pardal, "Steady-state drainage of an aqueous foam," Physical Review Letters, vol. 71, no. 16, pp. 2670-2673, 1993.

[48] D. Weaire, S. Findlay, and G. Verbist, "Measurement of foam drainage using AC conductivity," Journal of Physics: Condensed Matter, vol. 7, no. 16, pp. L217-L222, 1995.

[49] M. A. Helal and M. S. Mehanna, "The tanh method and Adomian decomposition method for solving the foam drainage equation," Applied Mathematics and Computation, vol. 190, no. 1, pp. 599-609, 2007.

[50] S. H. Mirmoradi, I. Hosseinpour, A. Barari, and R. Abdoul, "Analysis of foam drainage problem using variational iteration method," Advanced Studies in Theoretical Physics, vol. 3, no. 5-8, pp. 283-292, 2009. 


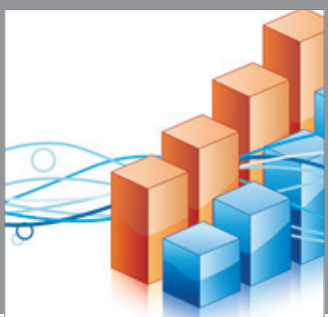

Advances in

Operations Research

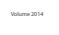

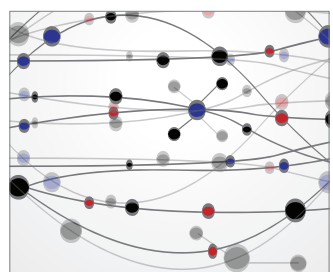

\section{The Scientific} World Journal
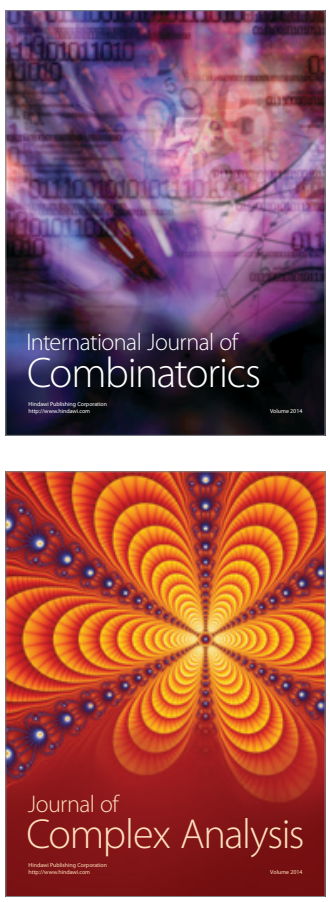

International Journal of

Mathematics and

Mathematical

Sciences
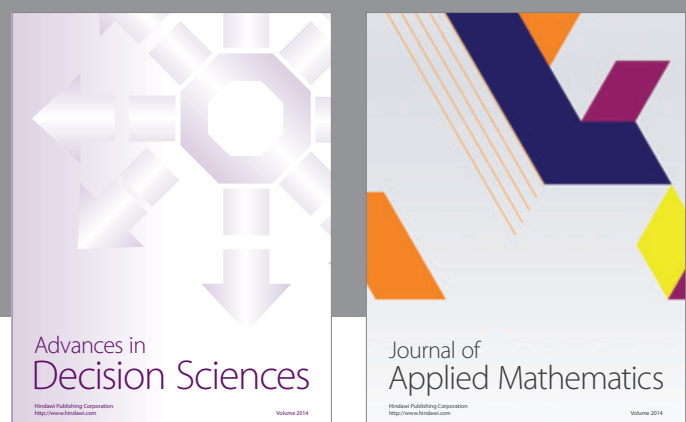

Journal of

Applied Mathematics
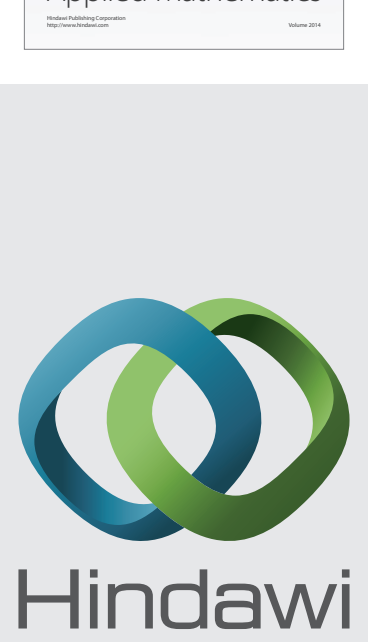

Submit your manuscripts at http://www.hindawi.com
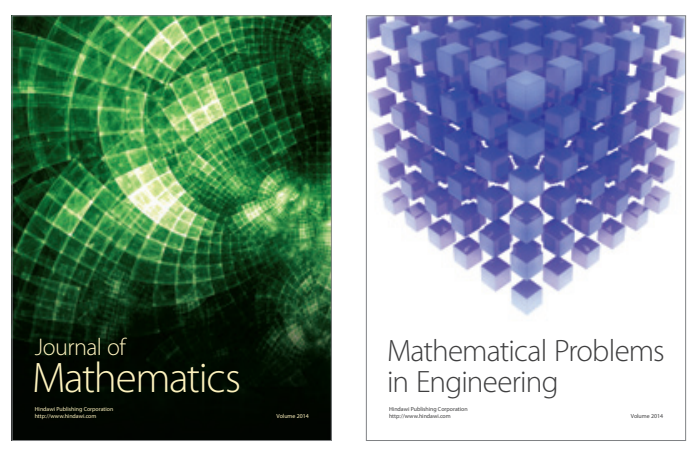

Mathematical Problems in Engineering
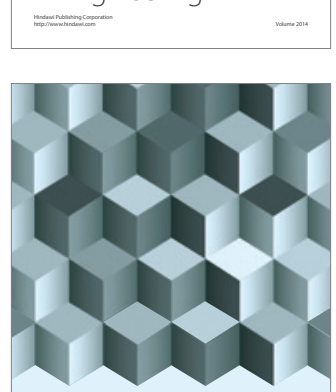

Journal of

Function Spaces
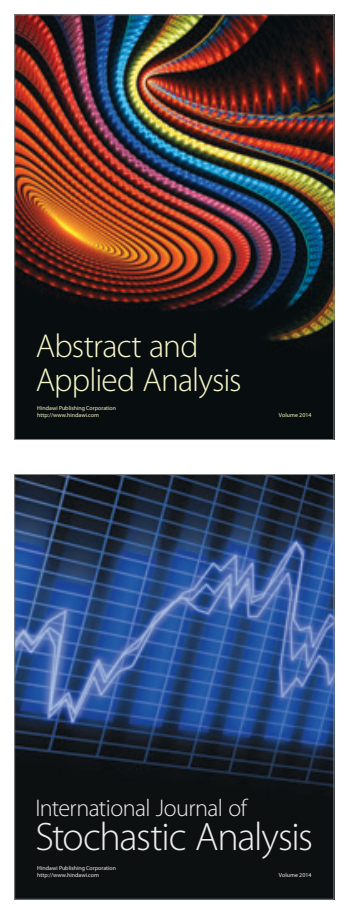

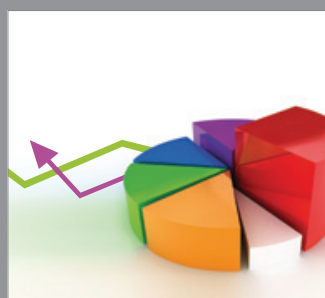

ournal of

Probability and Statistics

Promensencen
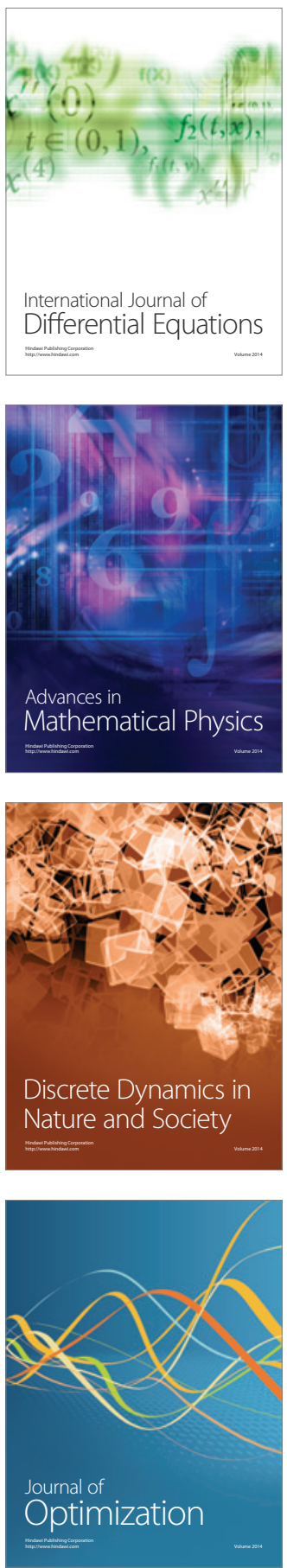